\title{
A simplified approach to the PROMETHEE method for priority setting in management of mine action projects
}

\author{
Marko Mladineo ${ }^{1, \uparrow}$, Nikša Jajac ${ }^{2}$ and Katarina Rogulj ${ }^{2}$ \\ ${ }^{1}$ Faculty of Electrical Engineering, Mechanical Engineering and Naval Architecture, \\ University of Split, Ruđera Boškovića 32, 21000 Split, Croatia \\ E-mail: 〈mmladine@fesb.hr> \\ ${ }^{2}$ Faculty of Civil Engineering, Architecture and Geodesy, University of Split, Matice \\ hrvatske 15, 21000 Split, Croatia \\ E-mail:〈njajac@gradst.hr,krogulj@gmail.com〉
}

\begin{abstract}
In the last 20 years, priority setting in mine actions, i.e. in humanitarian demining, has become an increasingly important topic. Given that mine action projects require management and decision-making based on a multi-criteria approach, multicriteria decision-making methods like PROMETHEE and AHP have been used worldwide for priority setting. However, from the aspect of mine action, where stakeholders in the decision-making process for priority setting are project managers, local politicians, leaders of different humanitarian organizations, or similar, applying these methods can be difficult. Therefore, a specialized web-based decision support system (Web DSS) for priority setting, developed as part of the FP7 project TIRAMISU, has been extended using a module for developing custom priority setting scenarios in line with an exceptionally easy, userfriendly approach. The idea behind this research is to simplify the multi-criteria analysis based on the PROMETHEE method. Therefore, a simplified PROMETHEE method based on statistical analysis for automated suggestions of parameters such as preference function thresholds, interactive selection of criteria weights, and easy input of criteria evaluations is presented in this paper. The result is web-based DSS that can be applied worldwide for priority setting in mine action. Additionally, the management of mine action projects is supported using modules for providing spatial data based on the geographic information system (GIS). In this paper, the benefits and limitations of a simplified PROMETHEE method are presented using a case study involving mine action projects, and subsequently, certain proposals are given for the further research.
\end{abstract}

Keywords: PROMETHEE method, project management, multi-criteria decision-making, decision support system, mine action

Received: September 9, 2016; accepted: December 11, 2016; available online: December 30,2016

DOI: $10.17535 /$ crorr. 2016.0017

$\dagger$ Corresponding author 


\section{Introduction}

Priority setting in managing mine action projects involves selecting humanitarian demining projects (mine action projects) which will have funding priority. Logically, this selection assumes that the projects with the highest priorities are selected. However, the question is: how to prioritize projects? This requires a transparent methodological process that includes all stakeholders. But designing this kind of methodology is not easy.

The main problem in designing a priority setting methodology has two different aspects: input data and definition of criteria. Figure 1 shows an illustration from the 'PriSMA' project [7] in defining criteria and input data which in turn provides an evaluation of the impact of mine clearance. The illustration shows how a SHA/CHA (Suspected Hazardous Area/Confirmed Hazardous Area) contaminated with mines and/or ERW (Explosive Remnants of War) reives a high or low priority depending on their impact on the population, infrastructure, vegetation, etc.

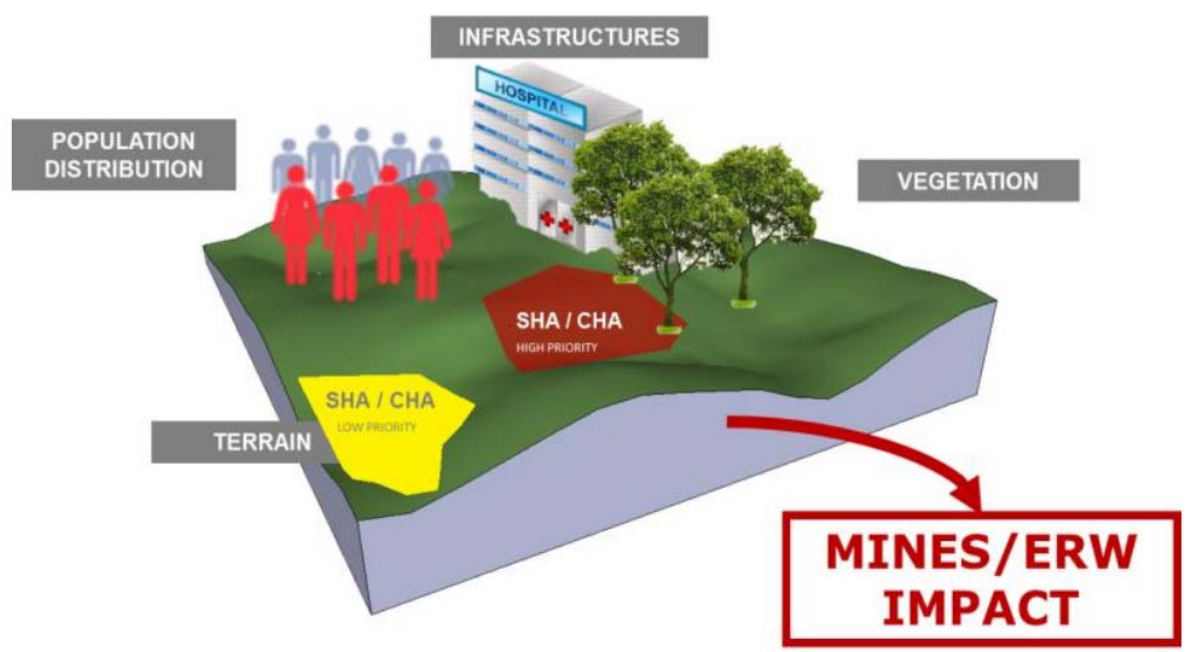

Figure 1: Defining criteria and evaluating the impact of mine clearance [7]

Input data represent evaluation of each minefield based on each criterion. Therefore, some of the data are spatial (area, terrain characteristics, vegetation, infrastructure, etc.) whereas other data are non-spatial (cost, number of victims, socio-economic impact, etc.), though the data are also connected in some way with certain spatial locations. Defining criteria poses a range of issues such as the criterion objective (minimization or maximization), the decision-maker's prefere- 
nces (certain thresholds or reference points), and the criterion weight (different weights or ponders used for different criteria).

Solving all these issues may possible lead to an exceptionally complex methodology and procedures. Therefore, transparent and methodological process require certain compromises. This paper presents a tool for customizing multicriteria analysis and the decision-making process in priority setting. It represents an interesting compromise for solving issues presented in this paper. As a part of FP7 project TIRAMISU [25], this tool was integrated into specialized the webbased decision support system, thus enabling stakeholders and donors to actively partake in the decision making process using a user-friendly and intuitive webbased application.

\section{State-of-the-art}

Generally, speaking, there is a need for priority setting in mine actions and has been clearly identified by numerous authors. Accordingly, it has been proven that the clearing of mine contaminated areas with a high priority [7] has a significant impact on the standard of living ([3], [5], [6]). Furthermore, priority setting increases sustainability of humanitarian demining, emphasizing not only economical aspect but also social and ecological aspects ([9], [10]).

During the last 20 years, MCA/MCDM methods have been used intensively in the management of mine action projects: from complete decision support systems ([1], [15], [20], [22], [23]) to the application of various MCDM methods ([4], [27]). However, a standardized approach or method has not yet been established. Therefore, an overview of MCA and MCDM methods is presented first. This is followed by an overview of approaches to priority setting in mine action management.

\subsection{Multi-criteria analysis and multi-criteria decision-making}

Multi-Criteria Analysis (MCA) and Multi-Criteria Decision-Making (MCDM) techniques and methods originated in the early 1980s. The main features of MCA/MCDM are: multiple criteria (attributes), conflicting criteria, incomparable criteria, and ill-defined problems. Solutions to MCA/MCDM problems require finding the optimal or most favorable solution, ranking alternatives from best to worse, sorting alternatives into classes, etc.

The main objective of these developed methods [8] since has been to help decisionmakers solve complex problems concerning criteria that are usually conflicting and qualitative. The underlying idea behind MCA/MCDM has been implemented in various fields solving a wide range of problems like selection, sorting, and ranking [14]. Multi-criteria models have become usual components in complex 
decision support systems [21], combined with other OR methods, decision models and spatial data management systems.

Nowadays, there are many MCA methods proposed by researchers and practitioners. However, some of these methods are well accepted due to adaptability to various problems and user-friendly environments, such as: AHP, PROMETHEE, ELECTRE and ORESTE. The crucial issue is deciding which method is most adequate for a specific problem.

The simplest and widely used method is weighted sum. However, weighted sum has difficulties in apprehending stakeholder preference adequately. The AHP method [24] uses pairwise comparisons to assess decision maker preferences regarding alternatives as well as criteria importance. It may possibly be useful for determining criteria weights as it eliminates inconsistency with decision makers. ELECTRE, PROMETHEE and ORESTE are outranking methods. The relative role attached to criteria in ELECTRE methods [22] is defined by two distinct sets of parameters: the importance coefficients and the veto thresholds. The second procedure consists of exploiting this outranking relation in order to identify a small as possible subset of actions, from which the best compromise action is selected. The ELECTRE family consists of several methods ELECTRE I, ELECTRE IS, ELECTRE II, ELECTRE III ELECTRE IV and ELECTRE TRI. PROMETHEE methods (PROMEHEE I, PROMETHEE II, PROMETHE V and the accompanying GAIA method) [2] are widely used due to their simplicity for implementation. Decision makers express their preferences for each criterion using six predefined preference functions covering a variety of situations. ORESTE methods [23] are based on the same concepts as ELECTRE. The procedure needs only ordinal evaluations of the alternatives and the ranking of the criteria in term of importance.

\subsection{Mine action project management and MCA}

Management of mine action project seeks the best option in terms of both mine clearance efficiency and cost effectiveness. The common problem is the selection of priorities, which must involve all stakeholders, thus enabling transparency of the ranking procedure. For donors, transparency increases confidence in the entire process.

Although the abovementioned problems clearly have MCA characteristics, there is lack of developed MCA/MCDM tools for mine action management. The following list provides an overview of applying multi-criteria methods to mine clearance problems:

- "MASCOT (Multicriteria Analytical SCOring Tool)" is a Spatial Decision Support System (SDSS) by GICHD [16] which applies Analytic Hierarchy Process (AHP) to help decision makers assess criteria weights during a ranking process. It is available as a free 'ArcMap' add-in. MASCOT was 
developed by the Geneva International Center for Humanitarian Demining (GICHD) in collaboration with the University of Geneva. The idea was to develop SDSSs in the mine action community. MASCOT ranks elements in terms of their Euclidian distance to a set of predefined criteria like: sensitive places, roads, infrastructures, land use types, slope, population densities etc.

- "GIS-based DSS for priority setting in humanitarian mine-action" by S. Knezic and N. Mladineo [14] is a comprehensive SDSS for prioritization of mine fields. The purpose of the research is to assess the relevance and effectiveness of the methods used to develop the pilot County Mine Action Plan in Croatia. For the purpose of priority assessment of mine action, the PROMETHEE I and II methods, as well as GAIA (Geometrical Analysis for Interactive Aid) were used. The software 'Decision Lab 2000', which supports the PROMETHEE and GAIA methods, was deployed. Data were generated using GIS. The authors concluded that the benefits of such an approach are the relatively small data collection costs using existing spatial data from GIS and the involvement of all stakeholders (either directly or indirectly) in the decision-making process, making this approach an advantage compared to the other methods. An additional benefit is the fully transparent approach which is preferable for donors. The same approach was used by authors in demining waterways in Croatia [20].

- "Selecting land mine detection strategies by means of outranking MCDM techniques" by I. De Leeneer and H. Pastijn [4] involves performing multicriteria analysis as a tool for selecting the best sensor combination in land mine detection from an airborne platform. Namely, a NATO study of the Advisory Group for Aerospace Research and Development (AGARD) on land mine detection from an airborne platform requested a selection process for the best sensor combination, and subsequently, the MCDM method was proposed. They used the ORESTE multi-criteria analysis method, a simple additive aggregation and the PROMETHEE method. The authors emphasized that selection criteria for land mine detection strategies were based on environmental conditions at the scenario as defined by the NATO industrial advisory group NIAG-D(96)8. The ORESTE multi-criteria analysis method was chosen, to avoid the need for quantitative assessments from experts. The results are compared with a simple additive aggregation and the results obtained from the 
PROMETHEE method. In comparing results from three methods, the authors pointed out the inconsistent ranking. They suggest further analysis with combinations of sensors and the use of criteria that differs from the environmental conditions.

- "Use of Multi-Criteria Analysis in Allocating EOD Teams in Humanitarian Mine Action" R. Keeley [13] endeavored to explore the way multi-criteria analysis (MCA) can help in planning the allocation of mobile explosive ordnance disposal (EOD) teams between regions in a humanitarian mine action program. The author emphasizes the importance of the MCA tool in situations where stakeholders should be involved in order to increase transparency of the decision-making process, such as selection of criteria and decisions on weights. In mine action management, transparency should help maximize donor confidence and thus help in drawing funds. The method used here is a simple weighted average and the introduction of a contamination Boolean variable 0-1. The final province score is divided from a total of all scores and resulting in a ratio whereby the EOD teams can be allocated. In the conclusion, the author points to one possible apparent limitation related to involvement of stakeholders in the planning process as it may require some degree of education of stakeholders in MCA techniques.

- "Decision Making to Prioritize Mine Clearance Projects in support of the U.S. Department of State Strategic Plan and National Policy Guidance" by James Madison University - MAIC and Office of Weapons Removal \& Abatement (WRA) of the U.S. Department of State [12] performed a costbenefit analysis of two demining programs that included mine clearance activities and suggested prioritization. Two mine-affected countries were chosen for data collection and the study, Thailand and Ethiopia. Given that the cost-benefit analysis assessed only quantitative impacts, the researchers took into account intangibles that also may have been important considerations in choosing the projects. Therefore, prioritization was considered within the context of socio-economic development programs. Firstly, a cost-benefit analysis model was performed. Additionally, researchers performed an analysis to choose the adequate MCA tool, the analytical hierarchy process (AHP). AHP was applied to the same projects. Criteria important in prioritizing projects on the basis of their respective contributions to socio-economic development were identified and assessed. The study team emphasized 
that the identified criteria were based on their research for the project. However, an added value could be further development of those criteria which decision makers believe were important for the goal.

- "Priority Setting Tool for Mine Action (PriSMA)" by GICHD [7] aims to enhance the ability of mine action stakeholders and partners in the broader human security sector in order to improve clarity on the impact of hazards, and thereby leading to better informed and more effective hazard reduction decisions. Priority setting is based on a definition of indicators and their weights. Indicators are thematic GIS layers representing socio-economic criteria (settlements, roads, infrastructure, etc.). A score is calculated for each indicator and aggregated sum of indicators represent the impact of mines and/or ERW (Explosive Remnants of War) on a certain area (high, medium or low impact). The tool is still under development and has been tested in Sri Lanka.

- "GIS-based Multi-Criteria Analysis of priority selection in humanitarian demining" by the University of Split and HCR-CTRO Ltd. [26] has been presented in a paper by M. Mladineo, N. Mladineo and N. Jajac [18]. It is a web-based DSS developed as a web-based application with a userfriendly interface for the easy inclusion of various stakeholders into the decision-making process. It has been developed as a part of the FP7 project TIRAMISU, and, together with 'PriSMA' [7], represents a very rare example of a fully operational priority setting tool with a userfriendly interface for the inclusion of various stakeholders. This paper presents further the development of this web-based application: a custom MCA tool for priority selection in mine actions with the ability of defining up to 12 criteria and an almost unlimited number of actions (minefields or demining actions).

\section{Methodology}

\subsection{Project management based on the web-based DSS}

The web application "GIS-based multi-criteria analysis of priority selection in humanitarian demining" was designed for worldwide mine action community as a part of a toolbox for the FP7 TIRAMISU project. The main idea was to create a simplified multi-criteria analysis using simplified data input. MCA is based on the PROMETHEE method, and input of GIS-based data. However, non-expert users 
will find the PROMETHEE method difficult to use. Furthermore, evaluation of criteria data can be problematic, too.

To solve the abovementioned problems, some compromises were made using different statistical and mathematical methods. The first compromise was to calculate PROMETHEE method parameters automatically using statistical analysis (as will be presented later in the paper). The second compromise was to make the input of data, for instance, minefield maps (even the one drawn by hand) very easy for non-experts. This was achieved using simple spatial georeferencing and accompanied by spatial data in KML/KMZ format.

\subsection{The PROMETHEE method}

The PROMETHEE method was developed by J. P. Brans and B. Mareschal in 1983 [2]. The input for the PROMETHEE method is a matrix consisting of a set of potential alternatives (actions) $A$, where each $a$ element of $A$ has its $f(a)$ which represents evaluation of one criterion. The PROMETHEE I method ranks actions according to a partial ranking, with the following dominance flows, for the positive outranking flow [2]:

$$
\Phi^{+}(\mathrm{a})=\frac{1}{\mathrm{n}-1} \sum_{\mathrm{b} \in \mathrm{A}} \Pi(\mathrm{a}, \mathrm{b})
$$

and for the negative outranking flow [2]:

$$
\Phi^{-}(\mathrm{a})=\frac{1}{\mathrm{n}-1} \sum_{\mathrm{b} \in \mathrm{A}} \Pi(\mathrm{b}, \mathrm{a})
$$

where $a$ and $x$ represent the actions from a set of actions $A$ (during the pairwise comparison of action $a$ with all other $n$ - 1 actions), $n$ is the number of actions and $\Pi$ is the aggregated preference index defined for each couple of actions.

The PROMETHEE I method gives the partial relation, and then the net outranking flow is obtained using the PROMETHEE II method which ranks the actions according to a complete ranking for calculated net flow [2]:

$$
\Phi(\mathrm{a})=\Phi^{+}(\mathrm{a})-\Phi^{-}(\mathrm{a})
$$

In terms of priority assessment, the net outranking flow represents the synthetic parameter based on defined criteria and priorities among the criteria. Usually, the criteria are weighted using criteria weights $w_{j}$ using the usual pondering technique:

$$
\Pi(a, b)=\frac{\sum_{j=1}^{n} w_{j} P_{j}(a, b)}{\sum_{j=1}^{n} w_{j}}
$$


where $P_{j}(a, b)$ represents preference of $a$ over $b$ for a given preference function of criterion $j$.

\subsection{A simplified approach to the PROMETHEE method}

There are two issues that make the PROMETHEE method difficult to understand for non-expert users: interpretation of results in the $[-1,1]$ interval, and defining the preference function and its parameters.

The net flow $\Phi$ of the PROMETHEE II method can be modified [19] somewhat to produce the output in the $[0,1]$ interval instead of the $[-1,1]$ interval:

$$
\Phi^{\prime}(a)=\frac{\Phi^{+}(a)+\left(1-\Phi^{-}(a)\right)}{2}
$$

This modified flow is called the net score $\Phi^{\prime}$ [19], and is subsequently multiplied by 100 to obtain results in the $[0,100]$ interval. The idea of presenting the PROMETHEE II method results as scores requires making MCA more understandable to non-expert users. Unsurprisingly, MCA/MCDM experts prefer to have insight not just into the original PROMETHEE II net flow, but also into the positive and negative flow of PROMETHEE I. However, non-expert users prefer a simplified representation of results.

Regarding the preference function type, only one type of function can be used to simplify application of the PROMETHEE method: a linear type accompanied by indifference and preference thresholds. Using only a linear type represents a linearization-based approximation used often in different statistical analysis.

The next step is to calculate automatically preference function thresholds. This can be done using two different approaches. The first approach sets the indifference threshold to zero and the maximal difference between criterion evaluations as the preference threshold. This approach is called 'Zero-Max'. The second approach calculates the mean value and standard deviation of a set of differences between criterion evaluations. Subsequently, the difference between the mean value and standard deviation is set as the indifference threshold, whereas the sum of the mean value and standard deviation is set as the preference threshold. This approach is called 'Mean-Std'.

Table 1 presents a case study involving the selection of an optimal location for a new power-plant. It is the case study from the 'Visual PROMETHEE' software [17] and will be used to compare its results with the results of the 'Zero-Max' and 'Mean-Std' approaches. It is a good example for comparison purposes as it consists of 6 criteria and 6 different types of preference functions. 


\begin{tabular}{|c|c|c|c|c|c|c|}
\hline $\begin{array}{l}\text { Criteria } \\
\text { name }\end{array}$ & $\begin{array}{l}\text { Man- } \\
\text { power }\end{array}$ & Power & $\begin{array}{c}\text { Inve- } \\
\text { stment }\end{array}$ & $\begin{array}{c}\text { Opera- } \\
\text { tion }\end{array}$ & Villa-ges & Safety \\
\hline $\begin{array}{l}\text { Criteria } \\
\text { weight }\end{array}$ & 1.00 & 1.00 & 1.00 & 1.00 & 1.00 & 1.00 \\
\hline $\begin{array}{l}\text { Criteria } \\
\text { type }\end{array}$ & Min & $\operatorname{Max}$ & Min & Min & Min & $\operatorname{Max}$ \\
\hline $\begin{array}{l}\text { 'Case } \\
\text { Study' } \\
\text { preference } \\
\text { function }\end{array}$ & $\begin{array}{l}U \text {-shape } \\
q=10\end{array}$ & $\begin{array}{l}V \text {-shape } \\
p=300\end{array}$ & $\begin{array}{l}\text { Linear } \\
q=50 \\
p=500\end{array}$ & $\begin{array}{l}\text { Level } \\
q=1 \\
p=6\end{array}$ & Usual & $\begin{array}{l}\text { Gaussia } \\
n \\
s=5\end{array}$ \\
\hline $\begin{array}{l}\text { 'Zero-Max' } \\
\text { preference } \\
\text { function }\end{array}$ & $\begin{array}{l}\text { Linear } \\
q=0 \\
p=54\end{array}$ & $\begin{array}{l}\text { Linear } \\
q=0 \\
p=380\end{array}$ & $\begin{array}{l}\text { Linear } \\
q=0 \\
p=800\end{array}$ & $\begin{array}{l}\text { Linear } \\
q=0 \\
p=7.7\end{array}$ & $\begin{array}{l}\text { Linear } \\
q=0 \\
p=7\end{array}$ & $\begin{array}{l}\text { Linear } \\
q=0 \\
p=9\end{array}$ \\
\hline $\begin{array}{l}\text { 'Mean-Std' } \\
\text { preference } \\
\text { function }\end{array}$ & $\begin{array}{l}\text { Linear } \\
q=14 \\
p=39\end{array}$ & $\begin{array}{l}\text { Linear } \\
q=107 \\
p=299\end{array}$ & $\begin{array}{l}\text { Linear } \\
q=202 \\
p=528\end{array}$ & $\begin{array}{l}\text { Linear } \\
q=1.9 \\
p=5.4\end{array}$ & $\begin{array}{l}\text { Linear } \\
q=2 \\
p=5\end{array}$ & $\begin{array}{l}\text { Linear } \\
q=2 \\
p=6\end{array}$ \\
\hline Unit & $\begin{array}{c}\text { personn } \\
\text { el }\end{array}$ & $M W$ & $M €$ & $M €$ & villages & level \\
\hline Italy & 80 & 900 & 600 & 5.4 & 8 & 5 \\
\hline Belgium & 65 & 580 & 200 & 9.7 & 1 & 1 \\
\hline Germany & 83 & 600 & 400 & 7.2 & 4 & 7 \\
\hline Sweden & 40 & 800 & 1000 & 7.5 & 7 & 10 \\
\hline Austria & 52 & 720 & 600 & 2.0 & 3 & 8 \\
\hline France & 94 & 960 & 700 & 3.6 & 5 & 6 \\
\hline
\end{tabular}

Table 1: Evaluation matrix for a case study of selection of optimal location for new power-plant [17]

Table 1 shows the parameters and preference function type as given for the case study and the two 'Zero-Max' and 'Mean-Std' approaches. The net flow $\Phi$ from the PROMETHEE II method was calculated for all three examples and converted into the net score $\Phi^{\prime}$ using (5). The results are given in Figure 2. 


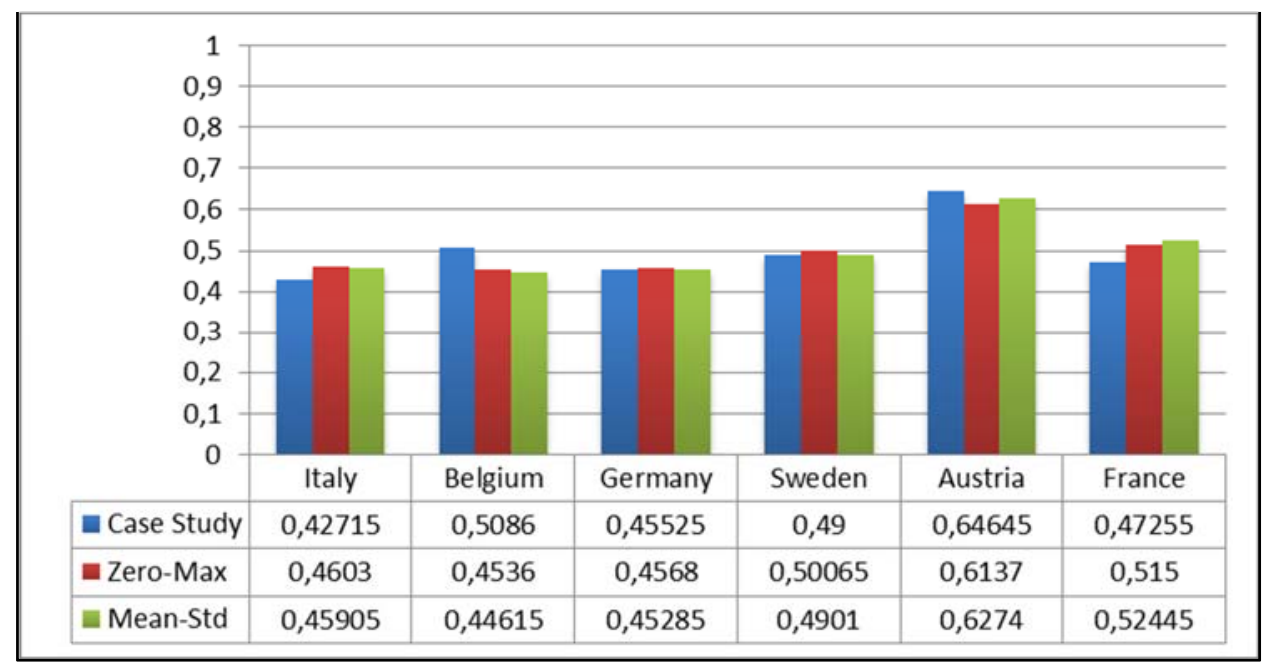

Figure 2: Defining criteria and evaluating the impact of mine clearance [7]

Figure 2 clearly shows that using only the linear preference function type and the two different approaches for automatic calculation of its parameters ('Zero-Max' and 'Mean-Std'), does not lead to a significant change in MCA results. The ranking has changed slightly, but the distribution of scores is very similar in all three examples. However, in this case study, the actions are very different and have a high variance of criteria evaluation. For actions with low variance (very similar actions), these approaches may produce an illogical ranking. However, in real-world application, such situations rarely occur especially in the case of mine action projects.

\section{Results}

The main features of the web application "GIS-based Multi-Criteria Analysis of priority selection in humanitarian demining" [26] are presented in [11]. Here were present a specialized tool for simplified MCA of mine actions, developed for the mine action community.

First, the input of data is necessary to define mine actions (minefields) and evaluate criteria data. Using the specialized 'GeoGate' tool, any spatial data in KML/KMZ format can be imported (Figure 3). 


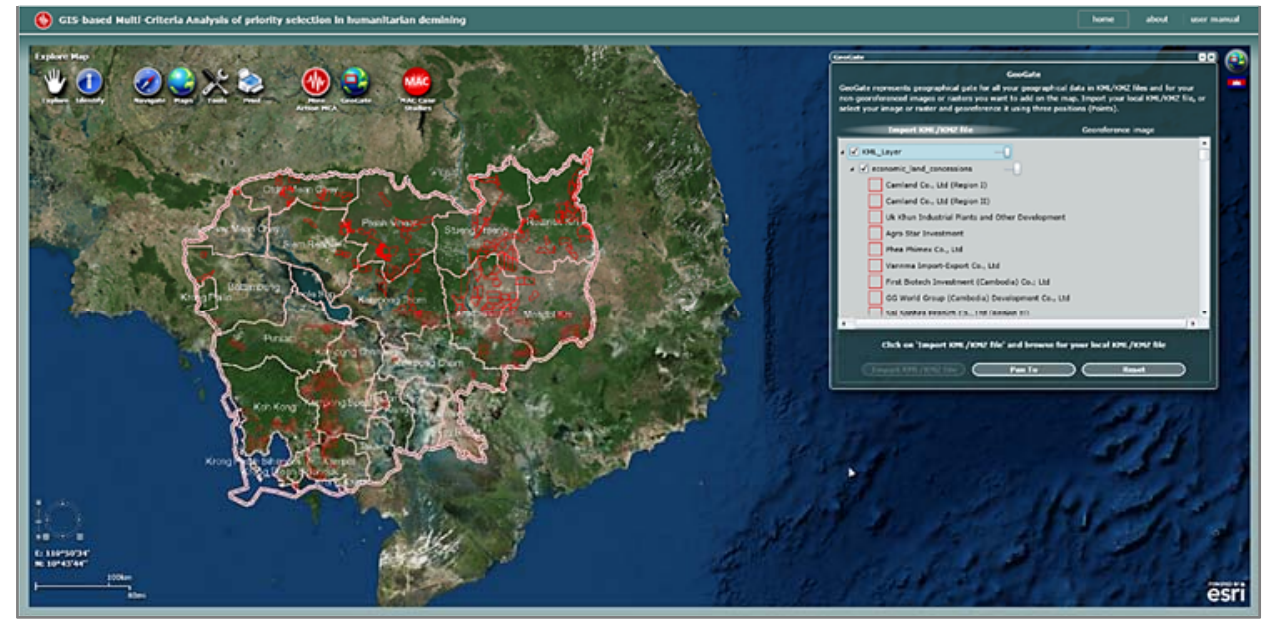

Figure 3: Importing data in KML/KMZ format using the 'GeoGate' tool

Furthermore, ordinary images that represent certain spatial data, but are missing spatial references (i.e. not geo-referenced), can be imported and geo-referenced. The user only needs to define three points on an image and then place these three points on the map. After that, automatic geo-referencing is performed the and image becomes spatial raster data (Figure 4). Hence, the 'GeoGate' tool enables the simple importing of data (maps) that are important in the priority selection process.

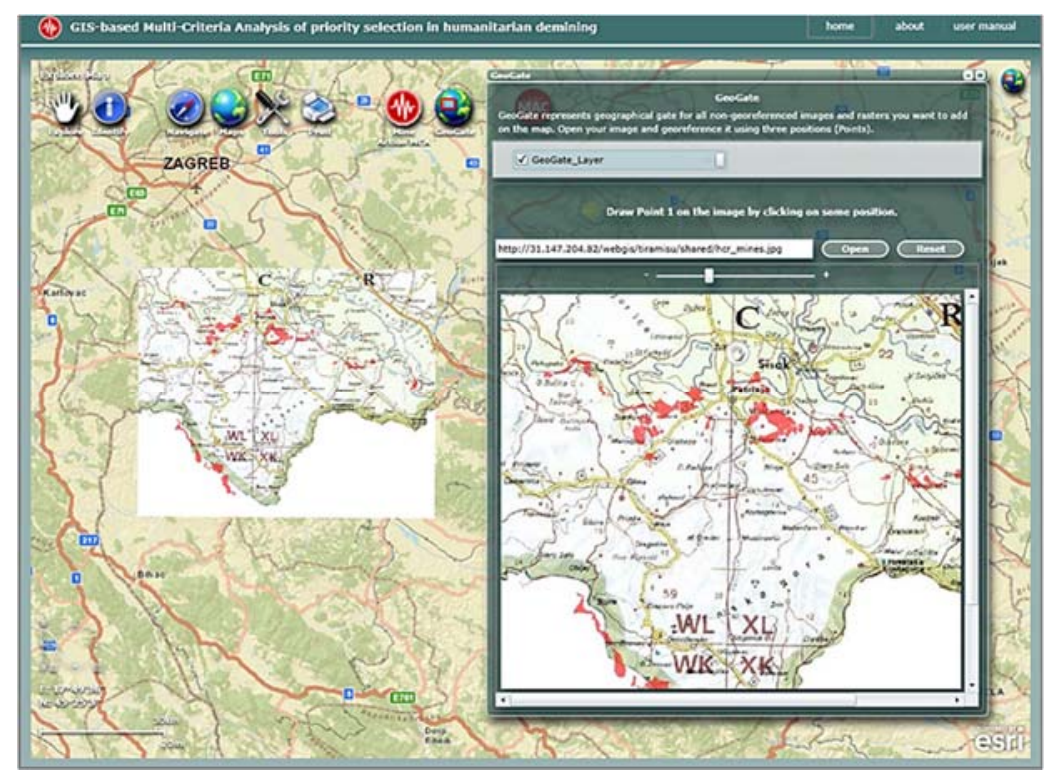

Figure 4: Geo-referencing of an image in JPEG format by defining three spatial points 
The next step is creating a custom MCA for priority selection with the possibility of defining up to 12 criteria and an almost unlimited number of actions (Figure 5).

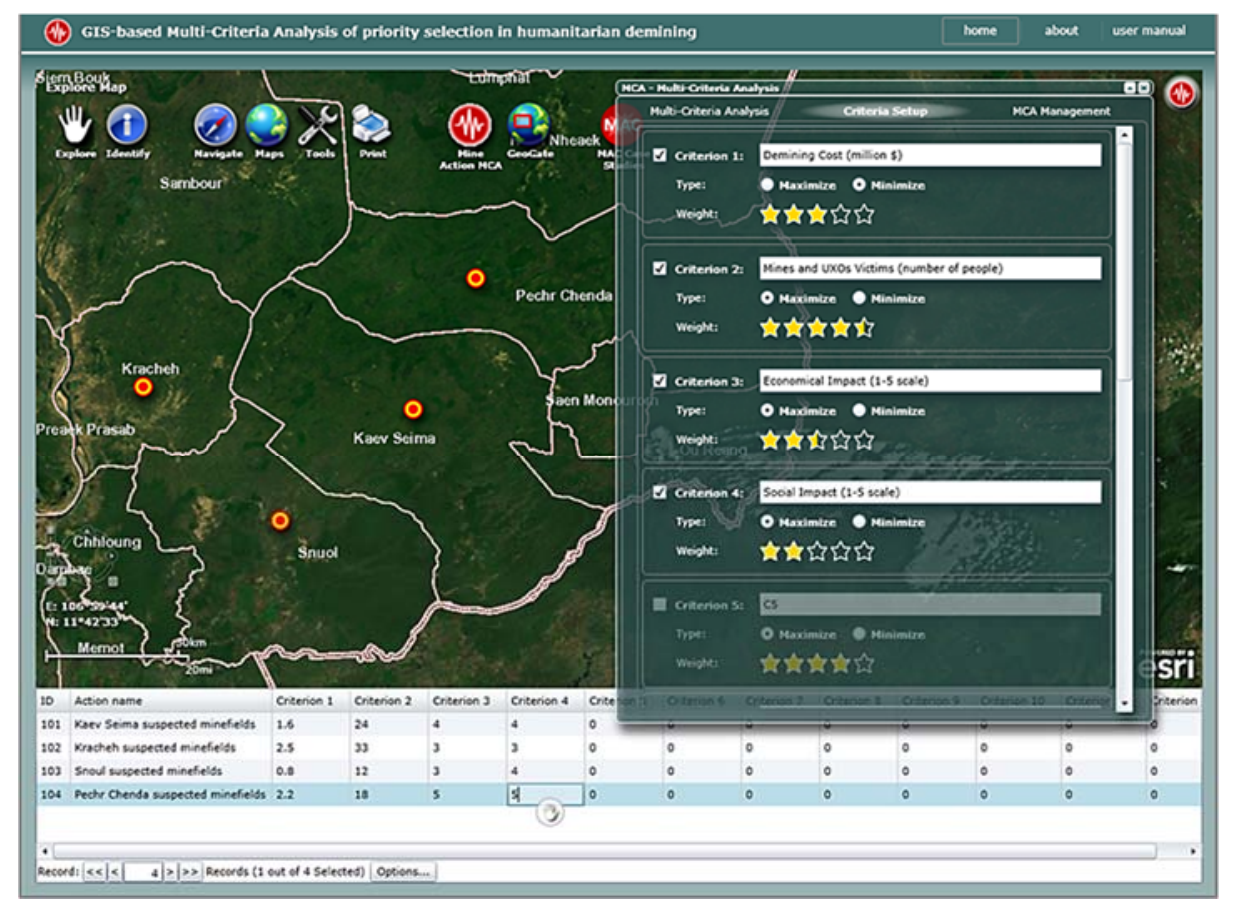

Figure 5: Creation of a custom MCA for priority selection with 4 actions and 4 criteria

This custom MCA tool allows users (the mine action community) to define actions (minefields) as points on a map in any part of the world. After that, a user can define up to 12 criteria and criteria evaluations for each action. A criteria type can be 'Maximize' or 'Minimize' depending on the optimization objective. For instance, the criterion 'Demining cost' should be 'Minimize', because the action with a lower cost should have priority over that with a higher cost. However, when a certain socio-economic criterion such as 'Number of victims' is taken in account, it will be 'Maximize', because actions with the highest number of victims should have absolute priority in demining. The user also defines criteria weights on an predefined integer scale from 1 to 10 . This scale is presented with a star symbols (Figure 5). The user does not define the preference function type nor its parameters, given that the linear preference function is used by default and preference thresholds are automatically calculated using the 'Zero-Max' approach. Automatically calculating the parameters has limitations and potential problems. However, it does ensure that the user from the mine action community, which is 
usually a non-expert for MCA, is not doing something he or she is unfamiliar with, such as defining a preference function type and its parameters.

Therefore, this approach represents a compromise that enables non-expert users to apply the PROMETHEE method in a simplified way. Nevertheless, further on, this paper provides some suggestions for defining the criteria set for priority setting in mine action management, and the validation of the presented MCA tool.

\subsection{Defining the criteria set for priority setting in mine action}

From previous experience ([20], [21], [27]) in supporting the decision-making process in mine action, it becomes evident that more significant and applicable results can be obtained by focusing on decision-support for donors instead of national institutions. Donors are driven by different strategies, such as the high socio-economic impact of demining, compared to the strategies used at national mine action centers which may be, for instance, under enormous political pressure. Hence, multiple criteria must be defined. However, there are no standardized criteria in the mine action community for priority setting.

However, criteria for evaluation of mine action intervention have been defined and standardized ("IMAS 14.10: Guide for the Evaluation of Mine Action Intervention" [11]), which include:

- Relevance. The extent to which the objectives of an intervention are consistent with beneficiary requirements, country needs, global priorities, and donor policies;

- Efficiency. A measure of economic conversion of resources i.e inputs (funds, expertise, time, etc.) to results (outputs and outcomes);

- Effectiveness. The extent to which the objectives of an intervention were achieved, or are expected to be achieved, taking into account their relative importance;

- Impact. The positive and negative, primary and secondary long-term effects produced by an intervention, directly or indirectly, intended or unintended. The term final outcome may be substituted;

- Sustainability. The continuation of benefits from a mine action intervention after major assistance has been completed;

- Safety and quality. This relates principally to demining activities and covers whether the work was carried out safely and achieved the required standards of quality for the activity (i.e. technical survey, clearance, marking, etc.

Other common criteria that may be included for a mine action evaluation include [11]: 
- Value-for-money (economy, efficiency, and effectiveness);

- Cost-effectiveness (used for comparing alternative means for achieving comparable objectives);

- Cost-benefit (comparing alternative means for achieving alternative objectives, whether comparable or not);

- Client satisfaction for both men and women;

- Beneficiary satisfaction;

- Replicability (whether a project or program can be replicated in a differrent environment);

- Scalability (whether a project or program can be increased in size or 'scaled-up').

It is clear that these criteria, defined by IMAS 14.10, can be used for the opposite purpose: evaluation of future mine action interventions. The only challenge is to estimate criteria evaluations that cannot be assessed, such as efficiency, safety, quality, etc.

Therefore, the six main criteria proposed by IMAS 14.10 will be used in validating the developed tool for priority setting.

\subsection{Validation of the simplified PROMETHEE method for priority selection}

An important part of the FP7 project TIRAMISU is validation of each tool developed within project. The best way to validate this tool was to select priorities in a region where the priority setting was already performed in the past. Therefore, a case study with its own criteria set and selected priorities will be compared to a new priority setting performed using the developed methodology and a common criteria set defined by IMAS 14.10 .

The following validation process was established for the above:

- Purpose: Priority setting using common criteria set defined for the mine action community.

- Method: PROMETHEE II (simplified approach).

- Input: a priority setting case study ("Case Study from the SisakMoslavina County).

- Output: A new priority setting using common criteria set as defined by IMAS 14.10 .

The historical case study of a priority setting titled "Case Study from the SisakMoslavina County" consists of minefields grouped into 11 municipalities and 24 criteria into 4 groups: impact of terrain characteristics and infrastructure, economic impact, social welfare, and impact of land-mine risk reduction. The entire case study is presented in [18] and [20]. 
Using minefield data presented as evaluations of 24 criteria, three experts created new matrix by estimating scores for each of five out of six criteria defined using IMAS 14.10. Only the 'Safety and Quality' criteria not used was, due to the difficulty in estimating its evaluations. The output of this process is the matrix presented in Table 2 .

\begin{tabular}{|l|c|c|c|r|r|}
\hline $\begin{array}{l}\text { Criteria } \\
\text { name }\end{array}$ & Releva-nce & Impact & $\begin{array}{c}\text { Effecti- } \\
\text { veness }\end{array}$ & Effici-ency & $\begin{array}{c}\text { Susta- } \\
\text { inability }\end{array}$ \\
\hline $\begin{array}{l}\text { Criteria } \\
\text { weight }\end{array}$ & 8.00 & \multicolumn{1}{|c|}{6.00} & 10.00 & 6.00 & 10.00 \\
\hline $\begin{array}{l}\text { Criteria } \\
\text { type }\end{array}$ & Max & Max & Max & Max & Max \\
\hline Unit & $\begin{array}{c}\text { score } \\
(0-100)\end{array}$ & $\begin{array}{c}\text { score } \\
(0-100)\end{array}$ & $\begin{array}{c}\text { score } \\
(0-100)\end{array}$ & $\begin{array}{c}\text { score } \\
(0-100)\end{array}$ & $\begin{array}{c}\text { score } \\
(0-100)\end{array}$ \\
\hline Dvor & 49 & 44 & 39 & 36 & 39 \\
\hline Glina & 48 & 48 & 60 & 35 & 45 \\
\hline Gvozd & 38 & 40 & 37 & 47 & 38 \\
\hline $\begin{array}{l}\text { Hrvatska } \\
\text { Dubica }\end{array}$ & 38 & 43 & 48 & 37 & 40 \\
\hline $\begin{array}{l}\text { Hrvatska } \\
\text { Kostajnica }\end{array}$ & 38 & 41 & 39 & 40 & 38 \\
\hline Jasenovac & 42 & 50 & 54 & 59 & 42 \\
\hline Novska & 60 & 42 & 42 & 70 & 40 \\
\hline Petrinja & 58 & 73 & 73 & 74 & 68 \\
\hline Sisak & 67 & 47 & 44 & 61 & 48 \\
\hline Sunja & 66 & 77 & 69 & 49 & 88 \\
\hline Topusko & 41 & 40 & 40 & 36 & 59 \\
\hline
\end{tabular}

Table 2: A new evaluation matrix for the case study

The criteria weights were determined as an average value of a criteria group from the total 24 criteria, which for instance represents the 'Efficiency' criterion.

The new evaluation matrix was subjected to the PROMETHEE II method and compared with results of the case study (Figure 6). Although the ranking of actions changed, the distribution of scores remained quite similar in both cases. Small variances caused changes in the ranking, but the scores were similar. Therefore, this tool satisfies the validation process and it subsequently became a publicly available tool for the mine action community.

The Conclusion is that the ranking of actions cannot be taken for granted, but the scores of alternatives should also be incorporated in the analysis. Moreover, it is the scores, not the ranking, that can be used for the distribution of demining funds. 
a) New priority setting using developed methodology

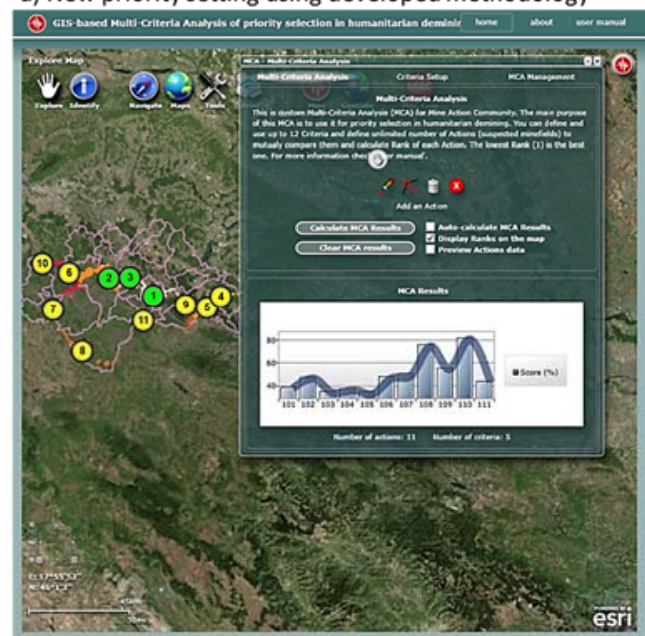

b) Historical Case Study of priority setting

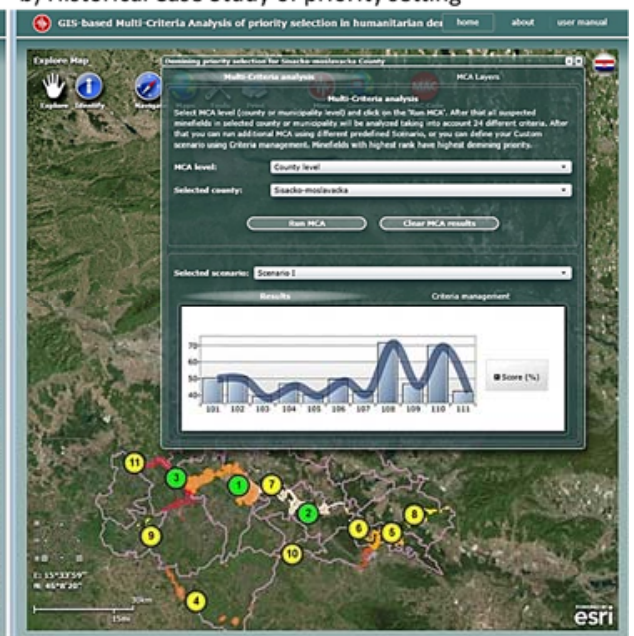

Figure 6: A comparison of the results from the new priority setting and the case study

\section{Conclusion}

The problem in applying the priority setting in managing mine action projects has two aspects: (1) defining the criteria set and applying the MCA method, and (2) the problem in estimating criteria evaluation for a defined criteria set. In this paper, both of these problems where addressed. The problem of defining a criteria set and applying the MCA method is solved by defining a common criteria set based on IMAS 14.10, whereas the problem of applying the MCA method is addressed by simplifying the PROMETHEE method and developing a web-based application "GIS-based multi-criteria analysis of priority selection in humanitarian demining". The problem in estimating criteria evaluations is solved by creating a module for incorporating different spatial data in GIS format (KML/KMZ files) and using a tool for simple geo-referencing of images in the form of certain maps or layers. An important part of the FP7 project TIRAMISU was validating this tool as developed within the project. Therefore, the conclusion is that the developed tool provides a similar distribution of priority scores compared to the case study involving the priority setting. Further research is to be based on a tool validation for a greater number of case studies and sensitivity analysis of criteria weights.

\section{Acknowledgement}

Research and development of the web-based application "GIS-based multi-criteria analysis of priority selection in humanitarian demining" was led by Prof Nenad 
Mladineo (FGAG, University of Split) in collaboration with HCR-CTRO Ltd., as a part of the FP7 project TIRAMISU.

\section{References}

[1] Benini, A.A., Conley, C.E., Shdeed, R., Spurway, K. And Yarmoshuk, M. (2003). Integration of different data bodies for humanitarian decision support: an example from mine action. Disasters, 27, 288-304.

[2] Brans, J.P., Mareschal, B., Vincke, P.H. (1984). PROMETHEE - a new family of outranking methods in multicriteria analysis. Operational Research IFORS 84, Amsetrdam.

[3] Davies, G. (2015). Living with landmines: mine action, development and wellbeing in post-conflict societies - a case study in Cambodia. Ph.D. Thesis, University of Bath, Bath, UK.

[4] De Leeneer, I., Pastijn, H. (2002). Selecting land mine detection strategies by means of outranking MCDM techniques. European Journal of Operational Research, 139, 327-338.

[5] Downs, C., Fox, A. (2016). Effectiveness and impact of UNDP mine action support: lessons learned. Journal of Conventional Weapons Destruction, 20.3, November 2016.

[6] Durham, J., Nanhthavong, V., Sychareun, V. (2016). Explaining how unexploded ordnance clearance enhances livelihoods in the Lao PDR. Evaluation and Program Planning, 54, 82-93.

[7] GICHD. (2016). PriSMA: Priority setting tool for mine action. Available at: http://www.mineaction.org/sites/default/files/documents/PriSMA\%20Prior ity\%20Setting\%20Tool\%20for\%20Mine\%20Action.pdf [Accessed 25/08/16].

[8] Guitouni, A., Martel, J.-M. (1998). Tentative guidelines to help choosing an appropriate MCDA method. European Journal of Operational Research, 109, 501-521.

[9] Gunawardana, H., Tantrigoda, D.A., Kumara, U.A. (2016). Humanitarian Demining and Sustainable Land Management in Post-Conflict Settings in Sri Lanka: Literature Review. Journal of Management and Sustainability, 6, 7990 .

[10] Hagenlocher, M., Hölbling, D., Kienberger, S., Vanhuysse, S., Zeil, P. (2016). Spatial assessment of social vulnerability in the context of landmines and explosive remnants of war in Battambang province, Cambodia. International Journal of Disaster Risk Reduction, 15, 148-161. 
[11] IMAS. (2016). The international mine action standard (IMAS) 14.10. Available at: http://www.mineactionstandards.org/about/archives/imasarchives [Accessed 25/08/16].

[12] James Madison University - MAIC and Bureau of Political-Military Affairs, Office of Weapons Removal \& Abatement (WRA), U.S. Department of State. (2004). Decision making to prioritize mine clearance projects in support of the U.S. Department of State strategic plan and National policy guidance. Harrisonburg: James Madison University.

[13] Keeley, R. (2003). Use of multi-criteria analysis in allocating EOD teams in humanitarian mine action. Journal of Mine Action, 7.1, April 2013.

[14] Knezic, S., Mladineo, N. (2006). GIS-based DSS for priority setting in humanitarian mine - action. International Journal of Geographical Information Science, 20, 5, 565-588.

[15] Krtalic, A. (2012). Levels of data within advanced intelligence decision support system (AI DSS). 9th Symposium Humanitarian Demining 2012, Sibenik.

[16] Lacroix, P., Santiago, H., Ray, N. (2014). MASCOT: Multi-Criteria Analytical SCOring Tool for ArcGIS Desktop. International Journal of Information Technology \& Decision Making, 13, 1135-1159.

[17] Mareschal, B. (2016). Visual PROMETHEE. Available at: http://prometheegaia.net [Accessed 25/08/16].

[18] Mladineo, M., Mladineo, N., Jajac, N. (2014). Project Management in mine actions using multi-criteria-analysis-based decision support system. Croatian Operational Research Review, 5, 415-425.

[19] Mladineo, M., Veza, I., Gjeldum, N. (2016). Solving partner selection problem in cyber-physical production networks using the HUMANT algorithm. International Journal of Production Research.

DOI: $10.1080 / 00207543.2016 .1234084$.

[20] Mladineo, N., Knezic, S. (2003). Decision support system for demining waterways. Journal of Mine Action, 7, 3.

[21] Mladineo, N., Knezic, S. Gorseta, D. (2003). Hierarchic approach to mine action in Croatia. Journal of Mine Action, 7, 2, 41-45.

[22] Roy, B. (1990). The outranking approach and the foundations of ELECTRE methods. Readings in Multiple Criteria Decision Aid. Berlin: Springer-Verlag.

[23] Roubens, M. (1982). Preference relations on actions and criteria in multicriteria decision making. European Journal of Operational Research, 10, 5155. 
[24] Saaty, T.L. (1980). The Analytic Hierarchy Process. New York: McGraw Hill. [25] TIRAMISU. (2016). FP7-TIRAMISU: Humanitarian Demining Toolbox. Available at: http://www.fp7-tiramisu.eu [Accessed 25/08/16].

[26] University of Split and HCR-CTRO. (2014). GIS-based Multi-Criteria Analysis of priority selection in humanitarian demining. Available at: http://tiramisu.maps.arcgis.com [Accessed 25/08/16].

[27] Van der Merwe, J. (2003). Priority setting for mine action. Journal of Mine Action, 7, 3. 